\title{
Risk assessment for forest fire in Brunei Darussalam
}

\author{
Shams Shahriar ${ }^{1,}{ }^{*}$, Zahran El-Said M. M. ${ }^{2}$, Said Safwanah N. M. ${ }^{1}$, Hui Kho J. ${ }^{1}$, Lee Naderah N. D. H. M. F. ${ }^{1}$, \\ Hasim N. H. H. ${ }^{1}$ \\ ${ }^{1}$ Civil Engineering Programme Area, Universiti Teknologi Brunei, Jalan Tungku Link, Gadong, BE 1410, Brunei Darussalam \\ ${ }^{2}$ Centre for Transport Research, Universiti Teknologi Brunei, Jalan Tungku Link, Gadong, BE 1410, Brunei Darussalam.
}

\begin{abstract}
The rise in global warming triggered by climate change and increased slush and burn activities particularly in Indonesia has been a major concern for deteriorating air pollution in Borneo regions in last two decades. Brunei Darussalam is facing increasing fire risk particularly during the dry season (February to April) of the year. The study is an effort to focus on the recent rise of fire events in Brunei Darussalam as fires can tremendously downgrade the quality of the country's well-known forestry; affect the economy and most importantly, health of the people. Geographical Information System (GIS) have been widely used by researchers to study fire risk assessment. The ArcGIS software is used for Optimized Hot Spot Analysis, Inversed Distance Weighted (IDW), and Kriging to compare and analyse the data and prepare a map for identifications of hotspot areas. High temperatures due to the El Niño phenomenon and low precipitation contribute greatly to the forest fire outbreaks. Results show that the Brunei-Muara district is mostly affected compared to Tutong and Belait districts. From the hotspots identified, the percentages of forest areas affected are 53\%, 64\%, 25\% in Brunei-Muara, Tutong and Belait districts respectively.
\end{abstract}

\section{Introduction}

There has been increased air pollution in Borneo regions (Mostly Indonesia) due to slash and burn as a simple method of clearing of forest for agricultural expansion by the farming community. The situation is further aggravated with prolong dry season due to increased temperature with very little precipitation as a result of climate change. Brunei Darussalam rich in biodiversity and tropical forest resources is increasingly more vulnerable to fire risk during lean period. Therefore, the present study gives emphasis on indentifying the risk for increased number of forest fire in Brunei Darussalam as fires can destroy the precious forest resources of the country, degrade the environmental quality particularly deteriorate air quality and cause significant economic loss in terms of property, infrastructure while impacting tourism and possess threat to human health as well as ecosystem.

The fire which occurs at forest and spreads very quickly is known as forest fire or wildfire. The fire usually occurs at forested area under rural or wild settings and rapidly spread from forest area to urban fringes disrupting transport links, posing a serious threat to nearby urban infrastructure like residential houses, with residents are in great danger to potential fire exposure. Forest fire is mainly caused by anthropogenic activities or by natural cause. However, forest fires resulting from anthropogenic activities are one of the major causes resulting from arson or deliberate act and in some cases accidental fire due to negligence. Smoking, requirement for expansion of agricultural land, activities like camping are some of the common causes of forest fire resulting from anthropogenic activities. Countries like Brazil, Indonesia, Mexico and Colombia often witness loss of forest cover due to slash and burn by the farmers for agricultural expansion. Indonesia itself has been a victim of slash of burn with a forest area of more than 261,000 ha in 2015 which lead to an alarming rise to air pollution due to haze generated from clearing of forest [1].

In fact, only a few percentage of forest fire is contributed by natural cause. Frequent dry lightning and further absence of precipitation, windy dry condition, prolong dry season are the causes of natural forest fires. According to National Interagency Fire Centre, 12\% of the forest fires occur because of lightning [2]. Besides, extreme hot weather and dry condition under the influence of El Niño leads to forest fire by removing moisture from the root zone of peat soil due to low humidity under prolonged dry season [3] and exposing

Corresponding author: shams.shahriar@utb.edu.bn 
dry leaves and branches of trees highly susceptible to forest fire [4].

The parameters such as temperature, precipitation, humidity, wind, slope, vegetation cover and soil types can greatly influence the intensity and spreading of fire [5]. Therefore, it is important to have adequate knowledge on those parameters to understand the fire risk assessment. Windy dry condition with steep slope, rapidly lead to quick spread of fire and burns large area of forest within a short time. Thus the fire fighters find it quite difficult to control forest fire under such condition and falls victims of fire casualty. The increased temperature also contributes to forest fire due to the heat which is one of three components (Fuel, oxygen, heat) for fire and results into quick spreading of forest fire. The dry grass, branches and leaves, peat soil which consists of organic matters quickly warm up when exposed to warmer climate and the root zone of the trees dries up with heat from the sun which makes fuels to ignite and burn faster, a major reason of spreading fire with lightning speed. Wind speed and its direction which contributes to the continuous and abrupt supply of oxygen makes the fire more intense and uncontrollable burning hectares of forest cover at an alarming rate. The situation further deteriorates while there is low humidity as the air comprises of low amount of water vapour consequently creating an environment for fire to start and spread faster.

One of the major concerns regarding the forest fire is that if the fire is not properly extinguished, it can easily get out of control taking heavy tolls on the surrounding environment which may persist for a number of days. In the long run, the restoration of ecosystem, flora and fauna and biodiversity is a great challenge once area is affected by forest fire. There is a potential of causing imbalance in nature resulting from forest fire and it takes even number of years for the nature to completely recover. Forest fire can result into the destruction of exotic plants and trees, a number of endangered habitats and wildlife in the Borneo region well known for its rich biodiversity and can lead to a large scale of deforestation [6]. Peat forests fire which continues to burn underneath the ground comprising dry organic components can cause nutrient deficiency in soils making the land unsuitable for growth of plants and trees and the land becomes barren. In fact, a number of cases of forest fires in Indonesia and Malaysia have led to harmful emission of carbon dioxide $\left(\mathrm{CO}_{2}\right)$, methane $\left(\mathrm{CH}_{4}\right)$, nitrous oxide $\left(\mathrm{N}_{2} \mathrm{O}\right)$, carbon monoxide $(\mathrm{CO})$ creating haze and thus polluting air. Particularly, the haze of 1997-1998, caused serious obstacles to air traffic movement, significant economic loos resulting from declined tourism and health affect in South-East Asia [7].

Brunei Darussalam has witnessed an increased number of forest fires during dry seasons i.e. from February to April. Fire and Rescue Department of Brunei Darussalam recorded a total of 1116 incidents of forest and grass fires in 2015 alone [8]. Fire risk evaluation has been identified as a crucial part and the leading task in fire management [9-10]. This research focuses on the underlying causes of forest fire in the context of Brunei Darussalam. Many researchers have used Geographical Information System (GIS) for forest fire risk assessment [11-12]. This study analyse the incidents of forest fire data and creates forest fire map with location of hotspot areas by using ArcGIS software.

\section{Countries Prone to Forest Fires}

An estimate by Intergovernmental Panel on Climate Change (IPCC) shows that on an annual basis, 75-820 billion hectares of land all over the world are burnt contributing to an average emission of 1.7-4.1 gigatons of harmful greenhouse gases (GHGs) into the atmosphere [13]. In Africa, a major concern arises from burning of grasslands for the purpose of land clearing and to convert it to agricultural land. According to African Forestry and Wildlife Commission, 9 million acres of land has been lost annually in the northern part of Angola due to frequent incidents of forest fire [14]. Even the Southern part of Europe such as countries like France, Spain, Italy and Portugal known for tourism are vulnerable to forest fire during summer of the each year because of increased tourist and camping activities. An incident of forest fire destroying land area of 5,000 hectares [15] resulted into massive evacuations even in thousands both in France and Portugal. Strong winds followed by persistent dry weather conditions resulted into uncontrollable blazes in France's Provence region recently. North American countries like California in USA and British Columbia in Canada have been affected by the worst forest fire very recently. One of the largest forest fires in Canada was recorded in the year 20162017 and considered as very costliest disaster. Many South American countries like Brazil, Bolivia, Chile uses traditional technique of slash and burn for clearing of lands for expansion of agricultural lands and human settlements. The situation becomes even more catastrophic during the drought season due to uncontrollable fire causing massive damage to forest resources. More than 20 million hectares of land with an estimated economic loss of $\$ 15$ billion were result of forest fire in the year 1997-1998, due to the worst El Niño [13]. The incidence of forest fire in Indonesia in past two decades (1996 to 2016) has been in the news lime light. Neighbouring Southeast Asian countries such as Brunei Darussalam, Malaysia, Singapore, Cambodia, Philippines, Thailand, and Vietnam are all victims of haze and air pollution resulted from frequent forest fire. Australia is one of the most forest fire or bush fire prone countries with an average of 2,000 wildfires or bush fires annually [16] because of its hot and dry climate which intensifies the spread of fire particularly during drought period. A number of properties and agricultural land in Australia have been damaged and destroyed by the raze of forest fire causing significant loss to economy.

The incidence of forest fire in Indonesia has turned into a recurring event raising question in dealing with 
fire management. The underlying reason for recurring forest fire is the traditional and common practice of clearing land known as slash and burn, as the land is intentionally set on fire to make way for agricultural expansion and human settlements. The forest land area comprises of peat soil rich in organic contents and highly susceptible to fire and therefore, making the land to spread fire rapidly even underneath the ground and almost irresistible to extinguish fire. Brunei Darussalam, Malaysia, Singapore and Thailand were affected by the forest fire occurrence of Indonesia in 2015 that created haze with an estimated cost of $\$ 16.1$ billion [17]. Over 9.5 million hectares of land were devastated, by forest fire comprising of Java, Borneo, Sulawesi and Sumatra of Indonesia producing massive haze spreading over one million $\mathrm{km}^{2}$ and severely affecting over 70 million people's health with damages totalling about US\$5-10 billion [18].

\section{Methodology}

The necessary data of forest fire occurrence was collected from the Fire Brigade department and complied with the frequency of forest fire at different locations based on the coordinates (latitude and longitude) and identified each locations using Google Map. The fire incidents data saved in excel database is first opened in ArcCatalog to project the data. The excel data is opened and exported to dBase (single) to convert the whole file to dBase tables using ArcCatalog. This then creates a new output table in .dbf form. The location data is projected as necessary by ArcGIS making it compatible for its use in ArcGIS. The location points are plotted in ArcGIS using a basemap of Brunei Darussalam with lots of details. Besides data obtained from Google Earth, is overlain onto the basemap to get the forest and housing coverage.

In the next step, the data is assessed by Hotspot Analysis to evaluate the aggregated clusters. Three various methods: (i) Optimized Hot Spot Analysis, (ii) Inversed Distance Weighted (IDW), and (iii) Kriging are used in this study among the many types of Hotspot Analysis. The Optimised Hot Spot Analysis tool is found in Spatial Statistics toolset, under the Mapping Clusters toolset whilst the other two are found under Spatial Analyst toolset, under Interpolation.

High and low values of clusters are identified using all of the tools. Optimized Hot Spot Analysis is similar to another hotspot tool called Hot Spot Analysis (GetisOrd $\mathrm{Gi}^{*}$ ) that requires a more in-depth procedure to generate the map. However Optimized Hot Spot Analysis pre-sets the parameters based on the data, automatically aggregates incidents data and identifies scale of analysis that produces the most favourable or optimal hotspot analysis results. Both IDW and Kriging have similar procedure; however IDW depends on the distance to the predicted location and Kriging depends on both the distance between the measured points and the predicted location but also on the overall spatial arrangement among the measured points.

In Optimised Hot Spot Analysis, the projected data is chosen as the Input Feature and the Incident Data Aggregation Method chosen is snapping aggregation method so that it snaps nearby incidents to create weighted points. Other parameters are defaulted or preset. A density folder is created under Density Surface. This then creates a new attribute field called Gi_Bin which shows that statistical significance or confidence intervals of the data. The red areas indicates the hotspots, green represents cold spots whereas yellow are insignificant as shown in Figure 1.

According to ArcGIS website, IDW determines "cell values using a linearly weighted combination of a set of sample points". The projected data is chosen as the Input Point Feature and the $\mathrm{Z}$ value field selected is GiZScore as the $Z$ score for each feature report the statistical significance of the spatial clustering of values. A high $\mathrm{Z}$ score for a feature indicates a spatial clustering of high values and a low or negative $Z$ score indicates a spatial clustering of low values. The IDW procedure produces a map shown in Figure 2.

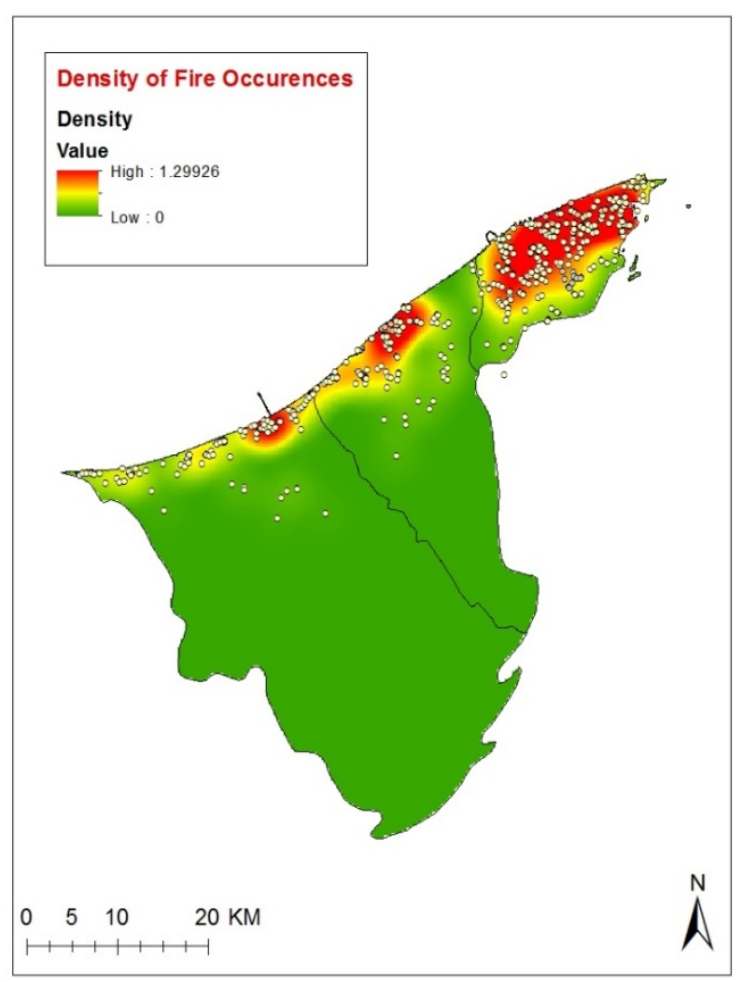

Fig.1. Map produced from Optimised Hot Spot Analysis

Kriging and IDW are more or less similar in terms of system but Kriging give emphasis on the geostatistical procedure which accumulates a set of points with zvalues into an estimated surface. In order to generate the output surface, the spatial behaviour represented by the 
Z-values has to be investigated before choosing the most suitable estimation method.

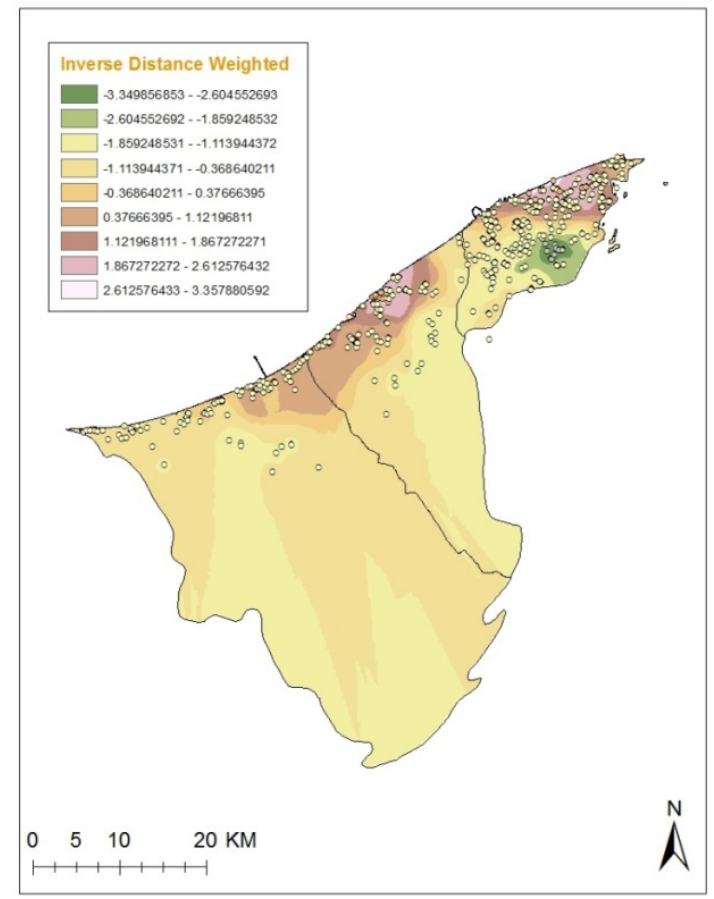

Fig.2. Map created from IDW

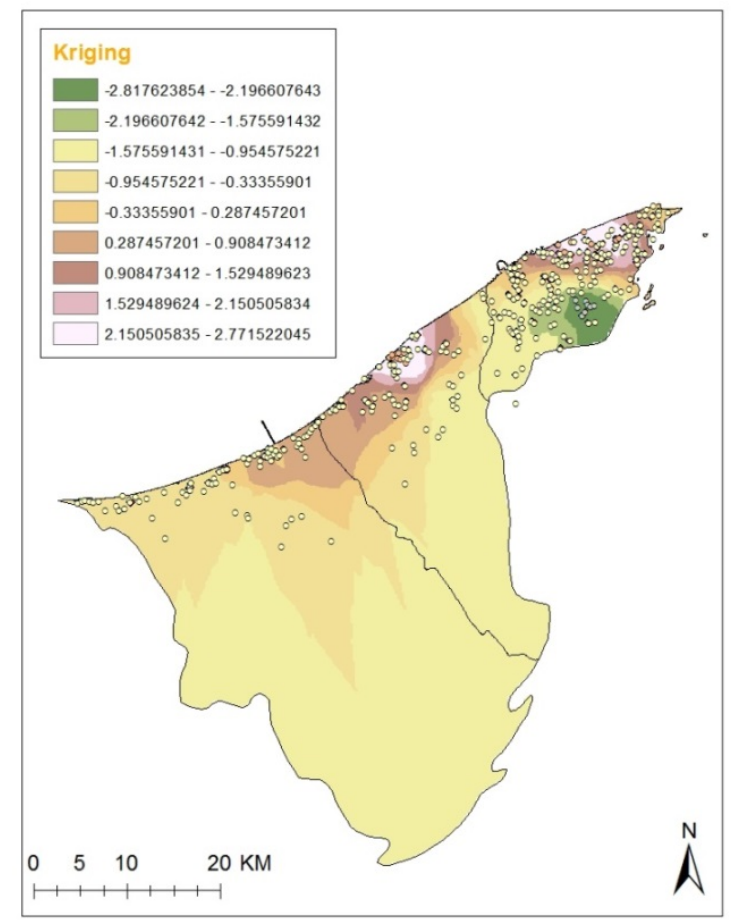

Fig.3. Map produced from Kriging

The IDW is directly based on the measured values which determine the levelness of the resulting surface.
Kriging is the next interpolation method which has the function to produce a predicted surface and some accuracy of the predictions. Kriging predicts a spatial correlation of the distance between sample points. It is a multistage process which consists of investigative statistical analysis of the data, modelling of variogram, creating the surface and exploring the variation in surface. Fig. 3 is the map produced from Kriging.

\section{Case Study: Brunei Darussalam}

The forest fire occurrence in Brunei Darussalam is influenced by its geographical location (Fig. 4), proximity to sea having strong wind, topography, soil types and climate. The climate of Brunei Darussalam is hot and humid in most of the year. It has an average minimum temperature of $24^{\circ} \mathrm{C}$ and a maximum temperature of $36^{\circ} \mathrm{C}$ during dry season while the temperature varies from $20^{\circ} \mathrm{C}$ to $28^{\circ} \mathrm{C}$ during wet season.

The coastal area in Brunei-Muara has lower altitude with humid tropical temperature varying from $20^{\circ} \mathrm{C}$ to $36^{\circ} \mathrm{C}$. The north of Tutong District has hot tropical climate while the south is relatively less warm and temperature varies from $22^{\circ} \mathrm{C}$ to $32^{\circ} \mathrm{C}$. Belait District which is mainly flat has slight warmer and temperature varies from $25^{\circ} \mathrm{C}$ to $37^{\circ} \mathrm{C}$. Lastly, Temburong District which is hilly in nature has humid subtropical climate and from the higher to lower altitude average temperature varies from $18^{\circ} \mathrm{C}$ to $29^{\circ} \mathrm{C}$.

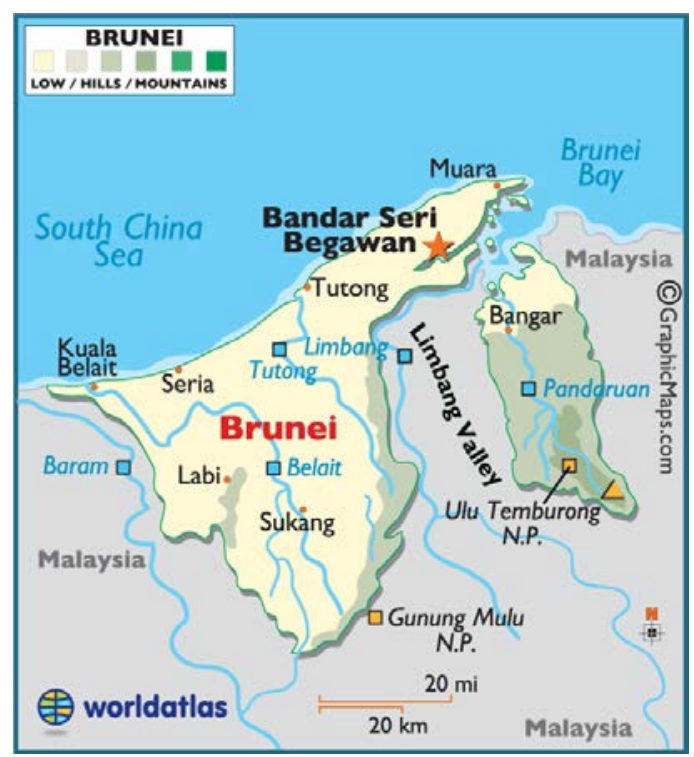

Fig.4. Location of Brunei Darussalam (Source: worldatlas)

The average precipitation in coastal areas of Brunei Darussalam is approximately $3,000 \mathrm{~mm}$ annually while towards inland and particularly in southern part of the country it can roughly exceed up to $4,000 \mathrm{~mm}$ [19]. The precipitation is generally more intense and heavy from 
October to January and less intense and light from March to August.

The landscape of Brunei Darussalam is mostly undeveloped and forested especially in the interior parts. The western parts of Brunei Darussalam are covered by hilly lowlands and thin forests while eastern parts are covered by thick forests and mountainous highlands particularly in the district of Temburong. The eastern parts are hilly, rising to $1,850 \mathrm{~m}$ in the peak of Mt. Pagon in the extreme south [20]. Most of Brunei-Muara District and the interior of the Belait and Tutong Districts are marked topographically by long ridges and cuestas. Flat and swampy plains under tidal affect cover the coastal area.

The soils of Brunei Darussalam are usually infertile and highly leached due to exposed weather condition. Some parts of river in the upstream and the coastal floodplain offer the best agricultural potential because of rich soil. White quartz sands are common in some areas of Tutong District.

Some parts of Brunei Darussalam's topography have not been fully investigated due to thick forests. The inner parts of the country are greatly covered by virgin rainforest. Thin sandy alluvial deposits or clay are usually found near the river banks and hilly areas while plains consist of peat swamps. The virgin tropical rainforest consists mainly of hardwoods, most of which are of commercial value. In the lowlands of the Belait and Tutong rivers, freshwater and peat swamps are found while mangrove swamps are common along the lower riverine reaches and sheltered coastal areas. The complex vegetation of the rainforest provides niches for a rich variety of animals. Land use of Brunei Darussalam in accordance with the National Master Plan, as stated on the Forestry Department website, shows that a large percentage of the land in Brunei Darussalam is used as forest reserves at about more than $55 \%$. Only less than $3 \%$ is used for agricultural purposes and conservation areas, and residential land consists of less than $5 \%$, with the remaining being Uncommitted State Land and other uses.

\section{Results and Discussions}

Extensive forest fires that eventually resulted in haze incident in 1998 has been a driving force for Fire and Rescue Department (Jabatan Bomba dan Penyelamat) of Brunei Darussalam to rethink and reassess on the issue of forest fire re-occurrence in the future. Table 1 shows the number of forest fire incident in Brunei Darussalam for year 2016. It can be seen from the Table that incidents of forest fire occurrences are more frequent during the months of February to April while it is less frequent during the months from June to August. However, the higher fire activities in the first few months are believed to be associated with the warm phase of ENSO phenomenon.
Most forest fire incidents in Brunei Darussalam are caused by human. However, temperature and precipitation are reported to aid in intensifying fire occurrences. The warmer and drier the weather conditions, the higher fire frequency in the area. The frequent incidents of forest fire are directly correlated with low precipitation and the principle cause of forest fire where dry period usually influence vegetations' flammability and make forest susceptible to fire. During these dry periods, amount of fuel available for generating fire will increase as trees become leafless while the balks and roots of the trees almost dries up due to absence of moisture. Moreover, the soil looses moisture as well and becomes dry which turns grass to become brownish and vulnerable to fire. The fire intensity can be further exasperated by strong dry wind leading to often uncontrollable fire spread due to mixing of more oxygen aided by strong wind.

Table 1 Number of forest fire cases in 2016

\begin{tabular}{|c|c|c|c|c|c|c|c|c|}
\hline Month & Jan & Feb & Mar & Apr & May & Jun & Jul & Aug \\
\hline $\begin{array}{c}\text { No. of } \\
\text { fire } \\
\text { incide } \\
\text { nts }\end{array}$ & 46 & 278 & 307 & 214 & 60 & 10 & 14 & 57 \\
\hline
\end{tabular}

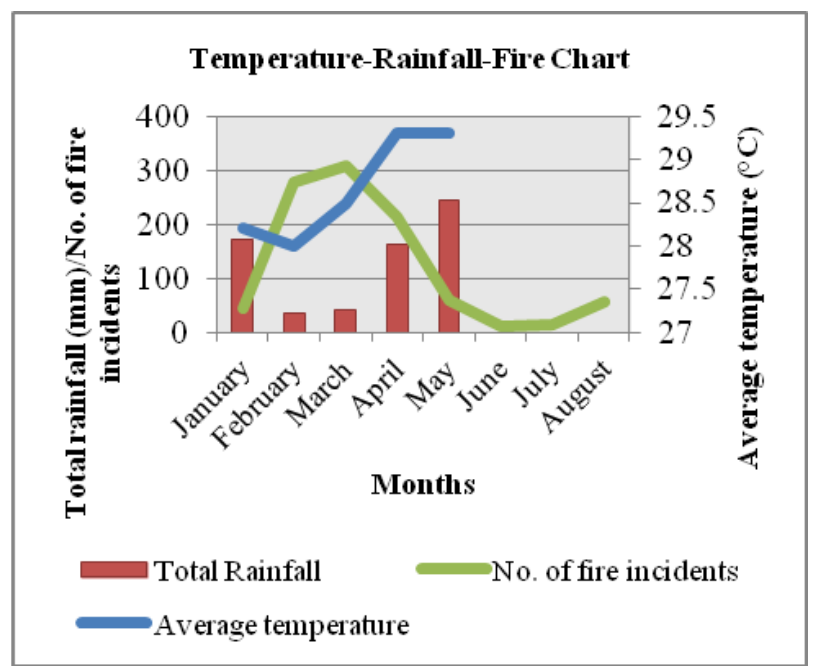

Fig.6. Correlation of the number of fire incidents with the meteorological data

From Fig. 6, it can be seen that the average precipitation, temperature, and the correlating fire occurrence show an apparent trend. Total precipitation and average temperate in the month of January are 172.3 $\mathrm{mm}$ and $28.2^{\circ} \mathrm{C}$ respectively while total precipitation and average temperate in the month of February is $36 \mathrm{~mm}$ and $28^{\circ} \mathrm{C}$ respectively. Thus the month of January is wetter and cooler as compared to the month of February and it is observed that the number of fire break outs in February is higher as compared to the month of February. Similarly, the months of March and April both have lesser precipitation and higher temperatures 
thus resulting into increased number of fire incidents, in comparison to the month of May which has a high precipitation of $243.9 \mathrm{~mm}$ and an average temperature of $29.3{ }^{\circ} \mathrm{C}$ leading to few incidents of forest fire.

This confirms that precipitation and temperature may have influence on frequency of fire occurrence; the higher the amount of precipitation, the lower the chances of a fire occurrence. Likewise, the higher the temperatures, the likelihoods of fire to ignite are higher. Combining the two factors together, lesser precipitation with high temperatures may result in higher fire frequency.

As shown in Fig. 7, Brunei-Muara is recorded to have the highest number of forest fire activities in 2016 with a total of 486 fire incidents. Whilst, Belait recorded the least with 226 cases. Brunei Muara is noted to have high fire occurrences between months February and August, while Belait and Tutong interchanges in other months. The graph in Fig. 7, shows that Brunei Muara is the most affected district in Brunei Darussalam.

Brunei Darussalam is densely populated at the northern part and forested at the southern part. However, increased number of fire incidents took place at the northern part of the country. Apart from Temburong, all the three districts in Brunei Darussalam have been identified with hotspots through Hotspots analysis. Bandar Seri Begawan, the capital of Brunei Darussalam has the largest hotspot. Tutong town is the main hotspot in Tutong and Seria bypass along the coastal belt in Belait is other hotspot area. These hotspots are found to be located in residential areas rather than forested areas, which indicates that the underlying major causes of forest fires are triggered by humans.



Fig.7. Fire incidents district wise
The incidence of forest fire occurrence is the largest in Brunei-Muara and the smallest in Belait. This may be due to the fire activities consistently occurring at the same area in Belait and Seria bypass. However, fires in Brunei-Muara are irregular, occurring in different area of the district, therefore, the hotspot is larger in comparison. Table 2 states the estimated burned areas obtained from Google Earth. The hotspot map from ArcGIS is overlaid onto Google Earth and the hectares of hotspot, residential area and forested area are outlined using the Polygon tool. The polygon areas are imported onto the earthpoint website to calculate the area of the polygons. The results shows that the percentage of burned area is more than $55 \%$ in Brunei-Muara, only $4 \%$ in Tutong and less than $1 \%$ in Belait. From the hotposts, the percentages of residential areas affected are $47 \%$, $36 \%, 75 \%$ in Brunei-Muara, Tutong and Belait respectively, with the percentage of forested land impacted are $53 \%, 64 \%$ and $25 \%$ respectively as shown in Table 2.

Table 2. Estimated hectares of the affected areas

\begin{tabular}{|c|c|c|c|}
\hline District & $\begin{array}{c}\text { Brunei- } \\
\text { Muara }\end{array}$ & Tutong & Belait \\
\hline $\begin{array}{c}\text { Total land area } \\
\text { (ha) }\end{array}$ & 54,749 & 121,667 & 278,216 \\
\hline $\begin{array}{c}\text { Hotspot area } \\
\text { (ha) }\end{array}$ & 30,280 & 4,804 & 3,473 \\
\hline $\begin{array}{c}\text { Residential area } \\
\text { (ha) affected by } \\
\text { fire }\end{array}$ & $\begin{array}{c}14,148 \\
(47 \%)\end{array}$ & $\begin{array}{c}1,733 \\
(36 \%)\end{array}$ & $\begin{array}{c}2,602 \\
(75 \%)\end{array}$ \\
\hline $\begin{array}{c}\text { Forest area (ha) } \\
\text { affected by fire }\end{array}$ & $\begin{array}{c}16,132 \\
(53 \%)\end{array}$ & $\begin{array}{c}3,071 \\
(64 \%)\end{array}$ & $\begin{array}{c}871 \\
(25 \%)\end{array}$ \\
\hline
\end{tabular}

It was mentioned in Methodology section that three different hotspot analyses were compared. IDW and Kriging are two of the methods that have nearly identical process and result. Their minor differences in their results are in which the Kriging requires additional procedures, such as spatial correlation and statistical map, to determine a more accurate map where the hotspots are more defined compared to IDW. In comparison, Kriging is better than IDW, but, overall Optimised Hot Spot Analysis is superior amongst the three because of the map is more transparent and comprehend and the procedures are simpler.

In most of the cases, the forest fire in Brunei Darussalam is regarded as Ground fires because of the consistent burning of peat soil rich in organic contents. Fire in peat soils burn and spread slowly in comparison to dried leaves, woods or branches of trees. Ground fires damage the ground cover of the forest floor and decrease the nutrients availability in the soil. This takes hundreds of years or century to build-up. One way to reduce the potential ignition of fires in peat area is to increase the ground water level. Firefighters need to inject water into the ground to raise the groundwater table to ensure the root zone of the trees and plants are wet enough with adequate amount of moisture restricting the trees to catch fire at its ground level. It is also recommended to dig trenches in the soil layer in order to disable fire to spread easily. 
In addition, it is required to modernise fire department with remote monitoring technologies for quick detection of fire and collection of data on the intensity and magnitude of fire and then apply the mitigation measure with prompt response to the fire affected area. The fire department should use fire risk system and should assess fire break outs with different classification to deal with different level of risks the fire threats may pose. The forest should be closely monitored around the period that fires are more likely to occur, especially during the El Niño season. It is crucial to forecast fires months before peak fire activity, as this could help in identifying locations with higher fire possibility for integrated planning in support of local actions.

Interview with Brunei Fire and Rescue Department officials reveals that, Seria bypass was one of the worst hit area by fire. There were plans to create a 'fire break' in the area in an attempt to create obstacle and prevent fire spread to other neighbouring areas. Fig. 8 (photo courtesy of the Fire Department) is an aerial view of the Seria bypass at $17-20 \mathrm{~km}$ mark showing proposed plans for a fire break. This sort of strategy to encounter forest fire at a number of locations can be effective method of tacking fire. The red line represents the proposed trench; blue line represents the road access for firemen and yellow line indicates the trenches to be filled with water.

Constraints encountered during the extent of the study include insufficient data was the core drawback. The data obtained from Fire Department was only for 8 months from the year 2016. In addition, the 8 months data provided did not cover information such as the damages due to fire, causes, time response, and magnitude of fire occurrence.

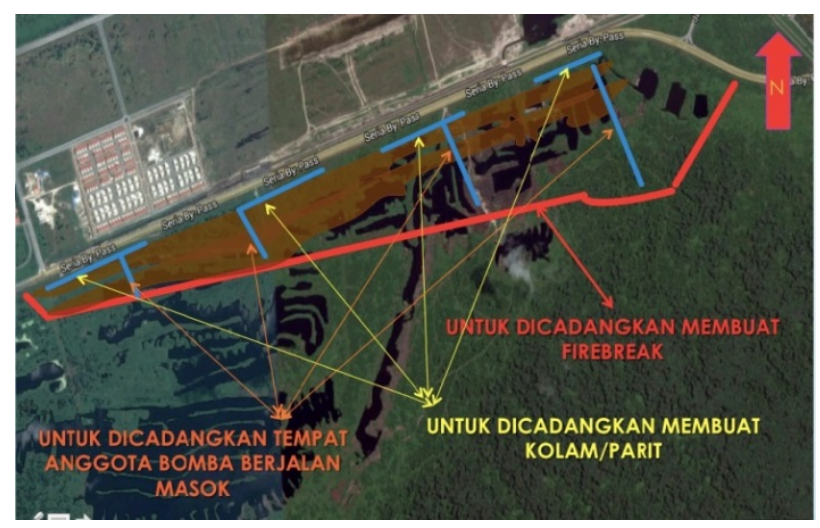

Fig.8. Plans from the Fire Department to create a 'firebreak' (Source: Brunei Fire Department)

\section{Conclusion}

Forest fire incidents were intensified in the early months of the year between February to April. High temperatures associated with the El Niño phenomenon and low precipitation greatly influence the fire regime. Results show that the Brunei-Muara district is the worst- hit district compared to Tutong and Belait districts. Therefore, large numbers of hotspots are found in the Brunei-Muara district. Moreover, most of the hotspots are located in the residential area which indicates humans are the common culprit that triggers fire ignition. This can either be due to throwing away of cigarette buds by careless smokers or irresponsible people openly burning waste or trash around the residential areas. Also, anthropogenic activities are responsible for forest fire in Tutong district involving smaller residential area. However, hotspot areas are the smallest in Belait district due to consistent occurrence of forest fire over the same areas of Seria bypass. Risk assessment indicates that the percentage of burned areas are more than $55 \%$ in the Brunei-Muara district, only $4 \%$ in Tutong district and less than $1 \%$ in Belait district. Hotspot analysis indicates that the percentages of residential areas affected are $47 \%, 36 \%, 75 \%$ in BruneiMuara, Tutong and Belait districts respectively. The study findings could have been more comprehensive if sufficient data of 10 to 20 years were available for the hotspot analysis.

\section{Recommendations}

In the event of fire incidents, Fire Department usually collects water through fire hydrants connected to pipe network system which is treated water. A large volume of treated water is actually used by the Fire Departments to extinguish fires. Therefore, planning should be done to avoid using treated water by having alternative options on the use of untreated water such as rainwater stored in reservoir, detention basins or other available surface water resources etc. This will reduce the cost of using treated water. Efficient planning in terms manpower management can assist in extinguishing fires, particularly during fire-prone months starting from February to April. More fire brigade personnel should be on guard during these months with focus on hotspots areas using high tech wireless remote monitoring system aided with drones, cameras, and sensors. Capacity building and training on forest fires can be initiated by recruiting volunteers and they can be mobilised during these months to assist prevention of forest fire, such as promoting awareness and weekly monitoring to ensure residents do not commit open burning. There are a total of 26 fire brigades stationed in Brunei Darussalam, including Temburong. It is essential that these fire brigades are stationed at fire-prone areas of fire-prone districts for immediate response. Presently, BruneiMuara is the most vulnerable to forest fire and assistance can be sought from other districts to deploy some of their fire-fighters to the fire-prone or hotspots areas in BruneiMuara. Similarly, fire brigades of Tutong District can be mobilised and stationed in Seria bypass of Belait District, especially during the El Niño season.

\section{Acknowledgement}

We extend our sincere thanks to Brunei Fire and Rescue Department, Department of Statistics (JPKE), Brunei 
Darussalam Meteorological Department (BDMD) and Survey Department for providing us data for this study.

\section{References}

1. The Guardian. Indonesia dismisses study showing forest fire haze killed more than 100,000 people. Available at https://www.theguardian.com/environment/2016/sep /21/indonesia-dismisses-study-showing-forest-firehaze-killed-more-than-100000-people (2016).

2. M. Ahrens, National Fire Protection Association. (2013).

3. H. Janssen. El Nino-Fuelled Drought May Cause More Destructive Wildfires to Ignite Across Indonesia During Winter. Available at http://www.accuweather.com/en/weather-news/elNiño-drought-indonesia-wildfire-smoke-healthimpacts/53707647 (2015).

4. P. Lynch. El Nino could drive intense season for Amazon Fires. Available at http://www.nasa.gov/feature/goddard/2016/el-ni-ocould-drive-intense-season-for-amazon-fires (2016)

5. H. Herawati, J. R. González-Olabarria, A. Wijaya, C. Martius, H. Purnomo, R. Andriani. Forests. 6, 1476-1499 (2015)

6. S. Milanova. El Nino could drive intense season for Amazon Fires. Available at: http://www.ecoplum.com/greenliving/view/274? dispatch=gcontents/view/274 (2016).

7. $\overline{\mathrm{L}}$. Tacconi. Centre for International Forestry Research. (2003).

8. D. Norjidi, L. Mohamad, Borneo Bulletin, January 29, (2016).

9. E. Chuvieco, I. Aguado, S. Jurdao, J. MartinezVega. Int J Wildland Fire 23, 606 (2014).

10. N. Hamadeh, A. Hilal, B. Daya, P. Chauvet. IntelliSys 2015 - Proceedings of 2015 SAI Intelligent Systems Conference, 522-526 (2015).

11. A. C. Teodoro, L. Duarte. Int. Geogr. Inf Sci, 27, 699-720 (2003).

12. F. Sivrikaya, B. Sağlam, A. E. Akay, N. Bozali. Pol J Environ Stud. 23, 197-194 (2014).

13. J. Larsen. Wildfires by Region: Observations and Future Prospects. Earth Policy Institute. Available at www.earthpolicy.org (2009)

14. United Press International. Africa lead globe in Forest Fires. Available at https:/www.upi.com/Africa-leads-globe-in-forestfires/10871143931796/ (2006)

15. H. Morris. Wild fires in France and Portugal: advice for travellers. Available at http://www.telegraph.co.uk/travel/advice/wild-firesin-france-and-portugal-europe-travel-holiday-advice (2016).

16. Natural Disaster Association. Natural Hazards \& Disaster. Available at http://www.n-d-a.org/fire.php (Year Unavailable).

17. The World Bank. Reforming amid uncertainty. Available http://pubdocs.worldbank.org/en/844171450085661 051/IEQ-DEC-2015-ENG.pdf (2015).

18. P. F. Moore. ASEAN Regional Center for Biodviersity Conservation Workshop on Forest Fires: Impact on Biodiversity (2001).

19. D. S. N. A. P. A. Hasan, U. Ratnayake, S. Shams, Progress in applied mathematics in Science and Engineering Proceedings, $29^{\text {th }}$ September $-1^{\text {st }}$ October 2015, Bali, Indonesia, AIP Conf. Proc. (2015).

20. C. K. Grant, The Geology and Hydrocarbon Resources of Negara Brunei Darussalam. 11-13 (1984). 